\title{
Mato Grosso: um Estado, diversos falares
}

\author{
Mato Grosso: one State, several speeches \\ Mariza Pereira da Silva ${ }^{1}$ \\ Universidade do Estado de Mato Grosso
}

\begin{abstract}
- RESUMO: O multilinguismo caracteriza a existência, no interior de um mesmo território, de diferentes comunidades linguísticas. O objetivo deste artigo é mostrar através de um percurso histórico sobre o Estado de Mato Grosso, o multilinguismo que se instaurou nesse Estado nos últimos 50 anos e as consequências que isso vem causando no sistema linguístico da região, o mosaico linguístico que vem se tornando o falar mato-grossense. Para o desenvolvimento deste estudo, focou-se nas políticas de povoamento do Estado, processos migratórios e expansão territorial pelos quais Mato Grosso passou ao longo de sua história, principalmente na onda migratória provocada pela divisão do Estado em 1979. Apresenta-se aqui a área de estudo, e, para análise, focaliza-se na política de povoamento, nas ondas migratórias, como se deram e os efeitos por elas causados no sistema linguístico do Estado e, com base em elementos que dão sustentação teórica à área da pesquisa sociolinguística, busca-se entender a atual situação do falar mato-grossense. Os resultados do estudo apontam para a expansão territorial do Estado de Mato Grosso, seguida dos processos migratórios e da expansão populacional como fatores que muito contribuíram para a formação no interior do Estado de comunidades linguísticas, que levaram ao multilinguismo na região, contribuindo para que o Estado de Mato Grosso se tornasse um Estado com diversos falares.
\end{abstract}

- PAlAVRAS-CHAVE: comunidade linguística; multilinguismo; sociolinguística.

- ABSTRACT: Multilingualism characterizes the existence of different language communities within the same territory. This article's objective is showing, through a historical path, the multilingualism that has been established in the State of Mato Grosso for the last 50 years and the consequences that it has been causing in the region's linguistic system, the linguistic mosaic that has become the mato-grossense speech. For this study, we focused on the State's population settlement policies, migratory processes and territorial expansion which Mato Grosso went through throughout its history, mainly in the migratory wave caused by the division of the State in 1979. We presented the study area and, for analysis, we focused on the population settlement policy, migratory waves, and how the effects caused by them in the State's linguistic system took place. Besides, we sought to understand the current situation of the mato-grossense speech based on the elements that provided theoretical support to the research area, the sociolinguistics. The research results point to the territorial expansion of the State of Mato Grosso, followed by migratory processes and population expansion as factors that greatly contributed to the formation of linguistic communities in the interior of the State, which led to multilingualism in the region, thus making the State of Mato Grosso become a State with various speeches.

- KEYWORDS: linguistic community; multilingualism; sociolinguistics.

\footnotetext{
1 Doutora em Linguística pela Universidade Federal do Rio de Janeiro (2005). Professora do Faculdade de Educação e Linguagem. Campus Universitário "Jane Vanini”. Av. São João, s/n. - B. Cavalhada. CEP: 78200-000 Cáceres/Mato Grosso-MT, Brasil. E-mail: mariza.silva@unemat.br
} 


\section{Introdução}

A iniciativa de escrever este artigo partiu das minhas andanças pelo interior do Estado de Mato Grosso desde os anos 1990. Primeiramente, como professora de Língua Portuguesa da Educação Básica e posteriormente como professora universitária de Instituições privada e pública.

A minha experiência como professora de Língua Portuguesa/Linguística de uma Universidade multicampi como a Universidade do Estado de Mato Grosso, meus deslocamentos pelo interior do Estado a serviço da Instituição, como também as minhas andanças por diversos municípios na coleta de dados para os meus trabalhos de qualificação profissional - Mestrado e Doutorado -, muito contribuíram para a observação da diversidade linguística existente em Mato Grosso, me oportunizando conhecer vários municípios deste Estado, bem como suas histórias e culturas.

Este artigo tem como objetivo fazer uma análise preliminar do mosaico linguístico em que se tornou o falar mato-grossense com base no contexto histórico e sociolinguístico da região, considerando principalmente as grandes ondas migratórias pelas quais o Estado passou ao longo de sua história, desenvolver procedimentos que permitam entender a história de seu falar em seu contexto social, utilizando o passado para explicar o presente. De maneira que o presente e o passado são fontes importantíssimas para esclarecer a evolução do dialeto mato-grossense e entender o que está acontecendo com o falar do Estado.

Pretende-se, portanto, chamar a atenção para a situação sociolinguística do falar mato-grossense na atualidade, buscar identificar, descrever e situar as diferentes variedades linguísticas as quais o dialeto mato-grossense se diversifica, conforme a sua distribuição espacial, sociocultural e cronológica. Isto é, entender o comportamento linguístico dos falantes, no sentido de perceber como a língua está distribuída no interior do Estado, como ela está espalhada pelas várias comunidades de fala, mostrar as relações maiores da língua com a sociedade local, em um estudo que engloba a diversidade linguística em seu sentido mais amplo, procurando examinar a interação entre dois aspectos do comportamento humano: o uso da língua e a organização social. De forma a enfocar uma gama de tópicos correlacionados à organização social do comportamento linguístico, incluindo não só a linguagem em si, mas também as atitudes dos falantes, os valores simbólicos que as variedades linguísticas adquirem para os seus usuários.

Para conduzir melhor a análise e discussão do tema aqui tratado, é importante que se localize a área do estudo, isto é, o Estado de Mato Grosso com suas características geográficas, econômicas e político-sociais, tendo como foco o contexto histórico, cultural e linguístico.

\section{2. Área de Estudo e Contexto Histórico e Sociolinguístico da Região}

\section{1Área de estudo}

O Estado de Mato Grosso está localizado na região Centro-Oeste do Brasil. É o maior estado em extensão territorial da região e o terceiro maior do país. Tem uma área de $903378292 \mathrm{~m}^{2}$, coberta na sua grande maioria pela Floresta Tropical Amazônica, zonas úmidas e as planícies da savana. A região apresenta planaltos, planícies e 
chapadas. O Pantanal, extensa área úmida do Estado, alberga diversas espécies selvagens e é tida como a maior planície alagada do mundo.

Com uma população de 3,2 milhões de habitantes e com 141 municípios, suas principais cidades são Cuiabá, Várzea Grande e Primavera do Leste. Sua capital Cuiabá é um centro de viagens que remonta à corrida ao ouro do século XVIII.

O Estado se limita ao norte com os estados do Amazonas e Pará, a leste com os estados de Tocantins e Goiás, ao sul com o estado de Mato Grosso do Sul e a oeste com o estado de Rondônia e a República Federativa da Bolívia.

O clima é tropical semiúmido e as temperaturas variam entre $23^{\circ}$ e $26^{\circ} \mathrm{C}$ ao longo do ano, podendo chegar aos $43^{\circ} \mathrm{C}$ no verão. Os invernos são secos, com umidade relativa do ar ficando muitas vezes na casa de $10 \%$.

Sua hidrografia apresenta duas bacias hidrográficas a bacia Amazônica e a bacia do Tocantins. Tendo como principais rios: Juruena, Telespires, Xingu, Araguaia, Paraguai, São Lourenço, Piquiri, Cuiabá e Rio das Mortes. E suas microrregiões estão assim divididas:

- Mesorregião do Norte

- Mesorregião do Nordeste

- Mesorregião do Sudoeste

- Mesorregião do Centro-Sul

- Mesorregião do Sudeste

O Estado tem solo fértil e no quesito produção mineral, além de ouro e diamante, é alto-suficiente em calcário, sendo o maior produtor do país, com jazidas distribuídas por diversas regiões do Estado (SEPLAN-MT, 2005).

Rico na sua produção pecuária, o Estado concentra também sobre suas terras a evolução dos principais rebanhos (bovinos e bubalinos, ovinos e caprinos, suínos, aves e equinos, muares e asininos). É famoso também pela produção de leite e mel de abelha, e, através de seus rios, consegue se destacar na piscicultura.

Conhecido por suas terras férteis, o Estado de Mato Grosso é rico na produção de sementes, como soja e milho, além de ser o maior produtor de algodão do país, atraindo, assim, muitos investidores no setor do agronegócio.

\subsection{Contexto histórico da região}

Para historiadores como Siqueira 2002, as terras mato-grossenses inicialmente foram disputadas por portugueses e espanhóis em uma disputa maior que envolvia tratados entre Portugal e Espanha no que se refere à colonização da América. O Tratado de Tordesilhas proposto pela coroa portuguesa dividia o continente americano em duas partes, cabendo à Espanha a porção oeste do território e a Portugal a porção leste.

Mas, tanto espanhóis como portugueses disputaram o território americano com um único interesse ocupar o território e extrair, principalmente metais preciosos, travando inúmeras batalhas contra os povos que habitavam o continente, dizimando e escravizando o povo, impondo sua cultura, sobretudo a língua e a religião, destruindo quem oferecesse resistência.

Com o passar dos anos, segundo Siqueira, 2002, as fronteiras do período Colonial já não se restringiam à marcos geográficos e sim aos limites fixados pela movimentação dos homens no território. E assim foi o processo de colonização do 
Centro-Oeste de uma forma geral a partir de 1750 , as terras que pertenciam ao rei de Portugal e aquelas que pertenciam ao rei da Espanha.

O Tratado de Tordesilhas já havia se tornado sem efeito, pois o avanço dos portugueses para o Oeste estabelecera um outra fronteira sacramentada pelo Tratado de Madri, que tinha como princípio básico o uti possidetis, ou seja, "como possuis, continuais possuindo".

E em 1754, já por ocasião do Tratado de Madri, as terras mato-grossenses foram delimitadas como sendo de domínio português. Embora, nessa época, se observava a presença de espanhóis em terras mato-grossense. De maneira que aqui em Mato Grosso a disputa entre portugueses e espanhóis pela colonização do Estado se tornava evidente e não foi diferente de outras disputas que os envolveram, marcadas por exploração e batalhas contra os habitantes da região.

\subsubsection{A colonização de Mato Grosso e a primeira onda migratória}

Embora a colonização de Mato Grosso tenha ficado sob o domínio dos portugueses, a princípio, segundo historiadores da região, coube aos bandeirantes paulistas a conquista do Estado e o povoamento de suas terras. A partir da segunda metade do século XVIII, os bandeirantes paulistas, atraídos pelas riquezas minerais do Estado, principalmente o ouro, adentraram a região, conquistaram e povoaram o território de Mato Grosso.

Todavia, os portugueses no processo de dominação colonizadora, exploração territorial e política de povoamento em Mato Grosso importaram portugueses advindos, mais precisamente, do norte de Portugal e escravos da África, consolidando-se a ocupação europeia, apoiada no modo de produção extrativista.

O povoamento do território mato-grossense se deu com mais intensidade após a descoberta do ouro entre os anos 1719 a 1722, em que foi registrado um grande fluxo migratório advindo do Sudeste (São Paulo, Rio de Janeiro e Minas Gerais) e do Nordeste.

O Estado de Mato Grosso, que a princípio tinha uma extensão territorial bastante expressiva $1.231 .549 \mathrm{~km}^{2}$, para alcançar o desenvolvimento, precisaria de uma política de povoamento que foi criada, no período da colonização. As sesmarias, por exemplo, foi uma política de povoamento que dava concessão de terra para quem nela quisesse trabalhar, a partir daí, foi dado início à primeira onda migratória no Estado, que abriu as portas de Mato Grosso para uma leva de migrantes que sonhavam ter sua própria terra e garantir seu sustento.

\subsubsection{A divisão do Estado de Mato Grosso e a segunda onda migratória}

A grande extensão territorial do Estado de Mato Grosso, somada ao desenvolvimento desigual de seus municípios, políticas de incentivo e programa de desenvolvimento nacional, que favorecia mais a algumas regiões do que a outras, motivaram o surgimento no interior do Estado de movimentos divisionistas. Contudo, a divisão se concretizou apenas em 1977, através de uma decisão do então presidente Ernesto Geisel, mesmo depois de um século de discussões e movimentos prol-divisão, e só obteve sua concretização de fato dois anos depois, no ano de 1979.

Essa cisão territorial, que fez surgir dois estados independentes Mato Grosso e Mato Grosso do Sul, representou a concretização de anos de lutas históricas pela divisão 
do Estado, encabeçadas por lideranças políticas residentes no sul do Estado, hoje Mato Grosso do Sul.

Com a divisão, Mato Grosso do Sul, sendo o Estado Novo, logrou mais vantagens, visto que ficou com o maior número de municípios, 55 municípios, os mais desenvolvidos, e sem dívidas. Portanto, coube ao Estado de Mato Grosso enfrentar os rescaldos da divisão. Com um número pequeno de municípios, 38 municípios, os menos desenvolvidos, a maior extensão de terra, $901.420 \mathrm{Km}^{2}$, e o acúmulo de dívidas, ainda teve como tarefa fazer o Estado crescer e se desenvolver rapidamente, para, assim, reativar a confiança da população mato-grossense. Todavia, reerguer o Estado sem a infraestrutura necessária para um crescimento rápido se tornara uma missão impossível, de modo que Mato Grosso teve mais um vez que abrir as portas para mais uma leva de migrantes.

As terras mato-grossenses foram novamente abertas à colonização, e o Estado teve mais uma vez que enfrentar uma política de povoamento, em que suas terras foram novamente abertas à colonização, tendo que enfrentar mais uma grande onda migratória, a segunda grande onda migratória registrada ao longo de sua história.

Os migrantes começaram a chegar e fundar várias cidades no interior do Estado, mesmo sem a infraestrutura necessária. Siqueira, 2002, afirma que nesse período 38.262 títulos de terra foram regulamentados pela INTERMAT (Instituto de Terras de Mato Grosso) para os migrantes, que eram cadastrados e encaminhados para as suas áreas de colonização, onde fundavam comunidades que cresciam e se desenvolviam como se fosse uma continuação de seus Estados de origem.

Eram migrantes advindos das diversas regiões do país, que atraídos pela exploração das terras mato-grossenses e atendendo a programas especiais que o governo federal desencadeou no Estado, a partir da década de 1970, se instalavam nas diversas regiões de Mato Grosso para as quais eram encaminhados, para viverem da pecuária e da agricultura de subsistência. Hoje, os mais abastados exploram o agronegócio.

Espalhados por todo o interior do Estado, os migrantes instalados nas regiões sudeste e sudoeste de Mato Grosso se ocupam da exploração da pecuária; já os que se instalaram nas regiões norte e noroeste se ocupam da exploração de grãos (soja e milho), e do algodão.

\subsection{Contexto sociolinguístico da região}

Considerando o processo histórico da região, no período inicial da colonização do Centro-Oeste, período compreendido entre os séculos XVIII e XIX, Campos 2014:118 afirma que já era perceptível em Mato Grosso o contato entre línguas que contribuíram para a formação de seu dialeto. A língua portuguesa do colonizador, as línguas indígenas já existentes na região, a língua dos bandeirantes paulistas, a língua do contingente africano e a língua dos espanhóis fazem parte desse quadro formador. Para a autora:

Não é possível precisar quais fatores contribuíram diretamente na constituição linguística do dialeto cuiabano. Na colonização de Mato Grosso, a Baixada Cuiabana foi um local de encontro de línguas e variedades linguísticas diversificadas, em diferentes períodos. Conviveram línguas indígenas, o castelhano das fronteiras, o português dos bandeirantes paulistas, variante crioula dos negros escravos e as diversas variedades do português trazidas pelos sertanistas migrantes. Gradativamente, para se comunicar, todos tiveram que aprender o português como segunda língua. 
As comunidades criadas pelos migrantes nas suas áreas de colonização cada qual compartilha o mesmo espaço geográfico-social e o uso do dialeto ou variedade linguística. De forma que esses migrantes impõem sua cultura aos nativos, sua língua ou dialeto, provocando, assim, em alguma região do Estado, alternância de código entre os nativos ou até mesmo um estado de aculturação.

A crescente ocupação das diversas regiões de Mato Grosso a partir dos anos 1970, mostra uma grande expansão do território mato-grossense e a fixação de um diversificado contingente migratório, que contribuiu para a evolução da população estadual de forma tão rápida que segundo Siqueira 2002:212, no primeiro ano da nova administração 17 novos municípios foram emancipados seguidos a tantos outros com poucos anos transcorridos desse período, e com menos de 10 anos da divisão perto de 30 cidades novas já pontilhavam regiões distantes do Estado, enquanto outras cidades tradicionais revitalizavam-se. E quanto mais cidades novas eram criadas em Mato Grosso mais crescia o multilingusmo no Estado.

Se considerámos a afirmação de Bagno 2014:44, quando ele diz que "o multilinguísmo é bastante previsível em países muito extensos e com grande população", podemos até dizer que o multilinguísmo observado em Mato Grosso é previsível, se considerarmos sua extensão territorial e sua população. Pois, sendo Mato Grosso o terceiro maior estado do país em extensão territorial e tendo uma população considerável em decorrência da imigração, é compreensível que tenha se tornado um Estado multilíngue. Visto que para este autor, o multilinguísmo se verifica também em pequenas nações como Portugal, onde o português convive com o mirandês, e Luxemburgo, um país pequeno, com metade da área de nosso distrito Federal, mas que tem três línguas oficiais.

Campos 2014:23 não só reconhece o multilinguismo que se instaurou em Mato Grosso, principalmente a partir de 1970, como também reconhece o impacto que este causou no falar mato-grossense quando afirma:

Ao se pensar na cuiabania antes de 1970, quando se intensificou o processo de migração de pessoas de outros Estados para Mato Grosso, sobretudo do sul do país, percebe-se que essa cultura foi duramente impactada, pois o estranhamento que causou levou os de fora a menosprezarem seus valores, principalmente o jeito de falar, incomum para o resto do Brasil.

De fato, além do dialeto tradicionalmente falado em algumas cidades de Mato Grosso, existe também os dialetos de imigração, levados para os mais diferentes lugares do Estado, pelos grandes movimentos populacionais. No território mato-grossense as muitas variedades linguísticas existentes formam um conjunto de dialetos falados depois do dialeto tradicional.

Ainda na sua obra sobre o falar cuiabano, Campos apresenta uma mostra do dialeto cuiabano, considerando dados de fala de pesquisas feitas em Mato Grosso, que mostram as variedades que marcam o falar dessa região. As peculiaridades do falar mato-grossense sugeridas por Campos incluem:

a) Realização variável da concordância de gênero;

b) Ausência de artigo em certas construções sintáticas;

c) Traços fonético-fonológicos;

d) Traços do sistema de consoantes;

Segundo Campos 2014:118, o mato-grossense realiza nomes que para a norma padrão são femininos como masculinos. Exemplo: "Vou lá no mamãe"; "Minha vó inda é vivo"; "Banana frito na manteiga". 
Outra característica marcante no falar cuiabano é a ausência do artigo em certas construções sintáticas, como podemos observar nas realizações: "[Ø] Mãe dele foi embora pra Goiânia"; "[Ø] Cachorro mordeu [Ø] criança duro na perna".

\section{Tracos fonético-fonológicos}

vogais orais tônicas

\section{[a]> [a :] alongamento da vogal tônica}

Recurso estilístico em que a palavra é afetada por um valor expressivo, como por exemplo: acre [a : kri], molhado [moKa: du], entrar [îtra:];

[a] $>[\varepsilon]$ elevação de $a$ para $e ́$

Exemplos: relo [relu] ao invés de ralo, teipa [tripa] ao invés de taipa;

Realização de $\boldsymbol{e}$ fechado tônico antes de consoante palatal [e]

Exemplo: mês [me J], fez [fe $]$;

$[e]>[\varepsilon]$ alteração de $e$ para $e$

Exemplos: mexo [met $\mathrm{mu}]$, bebo [bebu];

$[\varepsilon]>$ [i] elevação de $e ́$ para $i$

Exemplo: sigue [sigi] ao invés de segue.

\section{Sobre vogais nasaladas tônicas}

\section{[ß̊̉] > [a:] alongamento e desnasalação da vogal.}

Segundo ALMEIDA 2005, este traço ocorre na fala do mato-grossense mesmo em vogal seguida de consoante nasal, muitos falantes tendem ao alongamento mantendo $o$ timbre aberto da vogal e neutralizando sua nasalidade. Recurso estilístico, em que a palavra é afetada por um valor expressivo. Exemplos: câmera [ka:mera], cantando [kẹta:nu]:

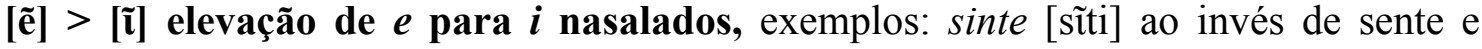
desminte [difmiti] ao invés de desmente;

[ẽ] $>$ [ẽj] ditongação

$\mathrm{O} e$ em posição final seguido de consoante nasal torna-se ditongo nasal decrescente, com o surgimento do assilábico [j], Exemplos: ninguém [nĩgẽj], também [tãbẽj], nem [nẽj].

Além desses, o ditongo [ẽj] aparece na sílaba tônica da palavra, por exemplo: engenho [ẽdzẽjyu].

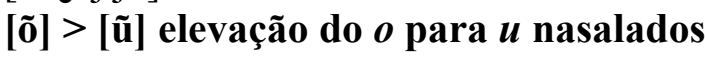

Exemplos: monta [mũta], como [kũmu]

Sobre as vogais orais átonas, os traços são:

[e] $>$ [i] elevação de $e$ para $i$

Elevação do e fechado para i em posição pretônica.

Exemplos: serviço [si.ðvisu], selecionado [silisjõnadu], seguinte [sigĩti], cearense [siarẽsu], terminar [trimĩna], merecimento [mirisimẽtu], dezesseis [dizese $\int$ ].

Elevação do $e$ fechado para $i$ em posição final e em monossílabos átonos:

Exemplos: doze [dozi], nome [nõmi], gente [dzẽti], diferente [deferẽti], irmandade [e.rmødadi]

$[\mathrm{e}]>[\mathrm{u}] /[0]$ alteração de $e$ para $u / o$

Realização de $[\mathrm{u}] /[\mathrm{o}]$ ao invés de [e]. Exemplo: semana [sumẽna].

$[\mathrm{e}]>[\tilde{\mathbf{l}}]$ elevação de $e$ oral para $i$ nasalado 
Alteração comum em posição inicial, principalmente se a vogal oral estiver seguida pela fricativa /z/.

Exemplos: existe [ĩzisti], exemplo [ĩzẽpu].

\section{[i] $>$ [e] alteração de $i$ para $e$}

Ocorre em sílaba pretônica com i inicial.

Exemplos: ermão [e.tmø̛w] ao invés de irmão [e.tmõ], irmandade [e.tmødadi] ao invés de irmandade.

Ocorre também com i medial: deversão [deved@ê] ao invés de diversão, deferente [deferẽti] ao invés de diferente.

[o] > [u] elevação de $o$ para $u$

Exemplos: dormir [du.tmi], bonita [bunita], política [pulitika], acostumado [kuftumadu], coberto [kube.tu], começo [kumesu], moreninha [murẽnĩa], porque [purke].

$[\mathbf{u}]>[\mathbf{u j}]$ ditongação

Exemplos: escuitei [ifkujtej] ao invés de escutei.

\section{Sobre vogais nasaladas átonas}

[ũ] $>$ [ũ] alteração de $u$ para $i$ nasalados

Exemplo: umbiguinho [ĩbigĩ].

\section{[aj] > [a] redução de ditongo}

Ditongos decrescentes orais e nasais

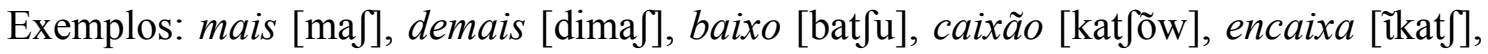
baixeiro [bat Seru], e também em bairro [baru].

[aj] > [عj] alteração de ai para éi

Exemplo: raiva [rejva]

[aw] $>$ [o] redução de au para o

Ocorre quando au encontra-se em posição átona, por exemplo: aumentando [omẽtøn], aumentou [omẽto], aumentado [omẽtadu].

\section{[ej] $>$ [e] redução de ditongo}

Exemplos: dezesseis [dizesef], seis [sef], deixaram [de Jaru], deixava [defav], peixe [pet5i], solteiro [sołteru], ferreira [fexera], toureiro [toreru], monteiro [mũtero], companheiro [kũpũyeru], porteira [pottera], graceira [grasera], primeiro [primeru], inteirar [îtera.t], barbeiro [ba.̧beru], etc.

\section{[ẽj] > [i] desnasalação e redução de ẽ i para $i$}

Em posição final, a vogal e seguida de consoante nasal, ao invés de realizar-se como ditongo nasal [ẽj], perde a nasalidade e reduz-se a [i]. Exemplos: vargem [va_tzi], coragem [koradzi], ontem [õti], homem [õmi], terraplanagem [texaprøjnadzi], viagem [viadzi], moagem [muadzi], parentagem [parẽtadzi], trampolinagem [trépulĩnadzi].

\section{$[0 w]>[0]$ redução de ditongo}

Exemplos: trouxe [trofi], tourada [torada], roupa [xopa], outra [otra], couro [koru], pouco [poku], fracassou, [frakaso], ficou [fiko], soube [sobi].

Conservação, variação e redução do ditongo [ẽw]

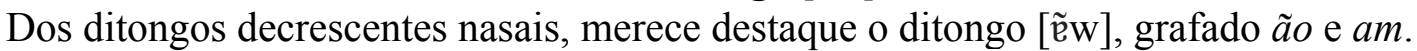

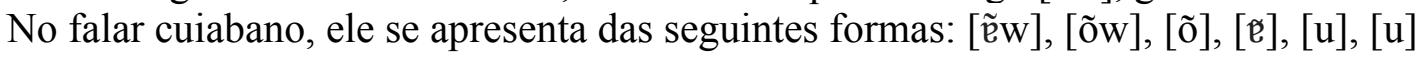

Exemplos: 
a) Conservação do ditongo [๕̄]:

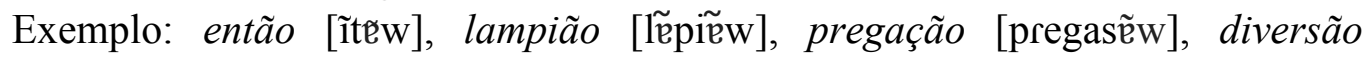

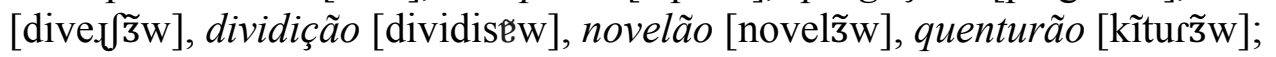

b) Conservação do ditongo, mas realização como [õw]:

Exemplo: valentão [valẽtõw], estão [iftõw], violão [violõw], caixão [katfõw], chão [t $\int \tilde{\mathrm{w}}$ ], rodão [xədõw], algodão [gudõw], fogão [fogõw], então [ĩtõw].

c) Redução do ditongo para [õ]:

Exemplo: chegavam [Jegavõ], então [itõ], criação [kriasõ], fazeção [fazesõ], queriam [kiriõ], gravação [gravasõ], reunião [riuniõ], chapadão [t fapadõ], João [dzõ], brigam [brigõ], mão [mõ].

d) Redução do ditongo para [๕]

Exemplo: falam [falæ], Sebastião [sebaftiø], trabalham [trabaא氏], então [ĩtø], não

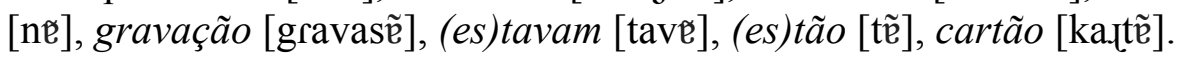

e) Redução do ditongo para [ũ]

Exemplos: não [nũ], estudaram [iftudarũ], vieram [viєrũ], largaram [la.jgarũ].

f) Redução do ditongo para $[\mathrm{o}] /[\mathrm{u}]$

Exemplo: notaram [notaru], deixaram [de Jaru], largaram [la.garu], brigaram [brigaru], levaram [levaru].

\section{Traços do sistema de consoantes}

$/ \mathrm{b} /$

Em alguns vocábulos, ocorre a alternância dessa consoante com /v/.

Exemplos: lavareda [lavareda] ou labareda [labareda].

$/ \mathrm{m} /$

Às vezes, essa consoante deixa de ser realizada, restando apenas a nasalação da vogal precedente.

Exemplos: uma [ũa], alguma [a.ıũa], numa [nũa].

$/ \mathrm{y} /$

Esta consoante costuma aparecer despalatalizada ou iotizada desnasalada.

Exemplos: minha [mia], minha [mĩa], historinha [iftorĩa], tinha [tĩa], senhor [sĩo], senhora [sĩo.], redondinho [xedõdĩ], padrinho [padĩu], igualzinho [igwazĩ], festinha [feftĩa].

$/ \mathrm{t} / \mathrm{e} / \mathrm{d} 3 /$

Com frequência, as consoantes fricativas pré-palatais surdas $/ \mathrm{J} /$ e sonoras $/ 3 /$ são pronunciadas respectivamente como africadas surdas $/ \mathrm{t} / \mathrm{e}$ sonoras $/ \mathrm{d} z /$.

Exemplos: chegar [tfega], chá [t $\left.\int \mathrm{a}\right]$, baixo [bat $\left.\int \mathrm{u}\right]$, cocho [kot $\left.\int \mathrm{u}\right]$, mexeriqueiro

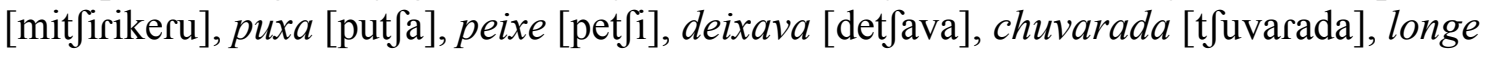
[lõdzi], gente [dzẽti], já [dza], rodagem [rodadzi], ajuda [adzuda], hoje [odzi], engenho [ĩdzẽjyu], junto [dzũtu], João [dzõ], trampolinagem [trãpulĩnadzi].

$/ 1 /$

O rotacismo (troca do $l$ por $r$ ) é um fenômeno bem marcado no falar cuiabano.

Exemplos: assembreia [asẽbreja], ao invés de assembleia; crareou [krario], ao invés de clareou; greba [greba], ao invés de gleba; pranta [prãta], ao invés de planta.

$/ \mathrm{r} /$

Há uma tendência no falar cuiabano de se realizar a vibrante múltipla, principalmente em posição inicial.

Exemplos: rapaziada [rapaziada], rasgar [rafga], reunião [riuniõ]. Em posição intervocálica, temos: correr [kore], carroça [karosa], burro [buru], curral [kura]. 
Para este estudo a mostra sugerida por Campos sobre os aspectos ou traços que caracterizam o dialeto cuiabano, ou falar mato-grossense, serviu de contraponto para uma comparação entre o dialeto das cidades tradicionais de Mato Grosso com os demais dialetos das cidades novas desse Estado, ao mesmo tempo que possibilitou também perceber nas cidades nas cidades novas a utilização ou não do dialeto tradicional da região.

\section{Metodologia e Discussão dos resultados}

\subsection{Procedimentos metodológicos}

Para se entender o multilinguísmo observado em Mato Grosso, provocado, principalmente, pela mobilidade geográfica através de ondas migratórias, foi necessário que se fizesse primeiramente um levantamento sócio-histórico da região, em seguida uma comparação de traços dialetais entre cidades antigas ou tradicionais e cidades novas, fundadas por migrantes, no sentido de mensurar a evolução da língua no Estado ao longo do tempo.

Para isso, se fez necessário o deslocamento da pesquisadora para cidades do Estado escolhidas como amostrais que tivessem essas características, a fim de captar a pronúncia atual dos falantes dessas cidades, focalizando traços fonético-fonológicos e prosódicos que pudessem identificar o dialeto característico das cidades tradicionais como também das cidades novas, fundadas depois dos anos 1970 e compará-los, com a finalidade de perceber mudança de pronúncias em cidades tradicionais para uma pronúncia difusa e divergência linguística nas cidades novas, por meio da qual grupos de falantes se distinguem dos demais, apresentando características do falar de suas regiões de origem. Isto é, investigar a hipótese de que as relações sociais atuam como variáveis no sistema linguístico da região e intervêm entre suas realizações na fala.

$\mathrm{O}$ estudo foi desenvolvido com base em métodos da sociolinguística interacional, ramo dos estudos sociolinguísticos associado ao trabalho de John Gumperz (1922-2013). No Brasil esse ramo da sociolinguística é representado por Stella Maris Bortoni-Ricardo, sua principal introdutora e divulgadora.

Apresenta uma análise cuidadosa dos traços específicos da fala de comunidades mato-grossenses, bem como das relações sociais subjacentes entre os falantes das comunidades. Retrata a diversidade linguística dessas comunidades e as operações em nível social e interacional. Para Blom e Gumperz (1986) "é na relação do dia a dia, nas múltiplas interações do cotidiano, que surgem sutis alternâncias de código". Considerando os falantes das comunidades pesquisadas e algum conhecimento relativo ao repertório linguístico desses falantes, espera-se poder relacionar esses repertórios ao seu comportamento verbal.

Para coleta de dados, foi utilizado o método da Observação Participante em 8 cidades amostrais, sendo 4 cidades consideradas tradicionais e 4 consideras cidades novas, fundadas por migrantes. Dentre as cidades amostrais tidas como tradicionais estão: Cáceres, Cuiabá, Poconé, Rosário Oeste, e dentre as cidades consideradas novas estão: Sinop, Colíder, Tangará da Serra e São José dos Quatro Marcos. Associados aos dados da Observação Participante, colhidos no período compreendido entre 2013 e 2014, foram utilizados dados fonético-fonológicos do falar mato-grossense, resultados de estudos desenvolvidos na região por pesquisadores, conforme lista sugerida por Campos 2014, e do estudo desenvolvido por Silva, 2005. 
Pretende-se, através dos dados, comparar o dialeto próprio das cidades tradicionais do Estado e os dialetos das cidades novas e assim checar a possibilidade de um processo de difusão lexical nas cidades tradicionais e uma divergência linguística relacionada às cidades novas, em que os falares se distinguem apresentando características do falar da sua região de origem.

Com base nestes tópicos, foram postuladas as seguintes hipóteses: a) os falantes mato-grossenses sofrem influências dialetais da fala do migrante; b) o migrante, emigrado para o Mato Grosso com as mesmas características sócio-demográficas mantém seu dialeto de origem inalterado. Hipóteses que buscamos esclarecer neste estudo.

As experiências e análise neste estudo demonstram a importância do significado social para o estudo da linguagem em sociedade. Percebemos que a simples observação naturalística do comportamento verbal não é suficiente. A fim de interpretar o que ouve e o que percebe na Observação Participante o pesquisador deve lançar mão de algum conhecimento prévio da cultura local, dos processos que geram o significado social, sem os quais o impossibilita fazer generalizações sobre as implicações sociais das diferenças dialetais.

Os processos que são demonstrados aqui são específicos de comunidades pequenas. Previsões sobre a manutenção ou a mudança linguística em sociedades menores, o destino do dialeto local, o contato de novas comunidades com este dialeto e a identificação dos falantes dessas comunidades com os valores da região.

\subsection{Discussão dos Resultados}

Os resultados da Observação Participante correlacionados a dados de pesquisas anteriores referentes ao dialeto mato-grossense mostram uma tendência difusionista em relação ao dialeto local de algumas cidades tradicionais ou mais antigas do Estado. $\mathrm{Na}$ cidade de Cáceres, por exemplo, e na capital Cuiabá, essa tendência já é bem evidente. Esses resultados mostram que essas cidades de Mato Grosso já estão sofrendo um processo de difusão, ou influências dialetais da fala do migrante quanto a alguns traços fonológicos e prosódicos, próprios do falar da região.

Essas cidades, ao que me parece, estão mais expostas ao contato de pronúncias diversas, Cuiabá por ser a capital do Estado, em que concentra um número maior de migrantes por oferecer maiores possiblidades e oportunidades e Cáceres que, por ser polo estudantil, concentra uma diversidade linguística considerável, visto que recebe todo ano um contingente estudantil tanto interno, das várias cidades do Estado, quanto externo, advindo de várias regiões do país. Para Calvet, 2002:35 "o plurilinguísmo faz com que as línguas estejam constantemente em contato. O lugar desses contatos, para o autor, pode ser o indivíduo (bilíngue, ou em situação de aquisição) ou a comunidade".

Quanto às demais cidades tradicionais do Estado, conforme a amostragem, em cidades da baixada cuiabana como Poconé e Rosário Oeste, observa-se que o dilato tradicional se mostra mais preservado. São cidades que se mantiveram mais isoladas de grandes centros por alguns anos, mesmo observando que as distâncias que as separam da Capital Cuiabá, por exemplo, não sejam tão significativas.

Sobre as cidades novas, ou seja, as que foram fundadas por migrantes, os resultados mostram que esses migrantes tendem a manter seu dialeto de origem inalterado. Podemos entender esse comportamento do migrante através de uma afirmação de Bortoni-Ricardo 2005:88 que sugere que a tendência evolutiva dos padrões de linguagem da população migrada vai depender do seu processo de 
mobilidade social. Os migrantes dessas novas comunidades mato-grossenses fazem parte da classe de migrantes integrados em redes de parentesco, os quais um parente veio primeiro se juntou a frentes desbravadoras, fundou a comunidade e com o tempo foi trazendo os outros, de forma que esses migrantes se mantiveram nas suas comunidades, mantendo seu dialeto e sua cultura inalterados.

Através da Observação Participante e de dados sócio-históricos da região é possível detectar o dialeto predominante em cada comunidade nova. Nas comunidades de Colíder e Sinop, por exemplo, localizadas na região norte do Estado, pode-se definir um falar sulista, até mesmo pela história que leva à fundação desses dois municípios. Em Colíder há uma predominância do falar paranaense, já em Sinop a predominância é do falar gaúcho.

O município de Colíder, conforme a história de sua fundação, segundo Ferreira, 2001:430 foi fundado pelo Sr. Raimundo Costa Filho, que já havia colonizado terras em parte do norte do Paraná, quando decidiu colonizar regiões de Mato Grosso pelo potencial agrícola dessas regiões. E com um grupo de pessoas do Estado do Paraná fundou a povoação de Colíder.

Já o município de Sinop tem uma história bem parecida com a do município de Colíder. É resultado de um projeto de colonização sob direção do Sr. Ênio Pipino, seu fundador, que através de sua empresa Sociedade Imobiliária Noroeste do Paraná fundou e colonizou Sinop juntamente com mais 400 homens entre topógrafos e trabalhadores provenientes da região Sul do Brasil.

Sobre o município de São José dos Quatro Marcos, situado na região Sudoeste do Estado, é fruto de atividades colonizadoras de paulistas, estes, em busca de terras boas para o plantio, foram chegando com suas famílias e fundaram a comunidade. Do mesmo modo que outras comunidades novas foram surgindo no interior do Estado e lá se constituindo, o mesmo ocorreu na região Sudoeste de Mato Grosso. Comunidades vão surgindo, formadas por um povo que, como tantos outros, atraídos pelas novas oportunidades econômicas, migra para o Estado, cria comunidades fechadas mantendo sua língua, sua cultura, sua educação. O dialeto predominante em São José dos Quatro Marcos é o dialeto paulista.

As relações pessoais observadas nessas comunidades novas têm todas as características de uma rede fechada (Ribeiro e Garcez, 2013 apud Barnes, 1954). Essa ausência de uma interação maior com o grupo local, mantendo a todo custo seu dialeto, sua identidade, sua cultura só reforça os significados sociais atribuídos ao dialeto para aqueles que partilham a mesma origem, a mesma identidade.

A metodologia da Observação Participante serviu para revelar uma série de traços dialetais encontrados nas comunidades novas que são fundamentalmente diferentes entre uma e outra comunidade, bem como a ausência de traços dialetais do falar tradicional mato-grossense. Em Tangará da Serra, por exemplo, na faculdade em que lecionei, era difícil até mesmo encontrar alunos do próprio Estado de Mato Grosso, em quatro turmas de quarenta alunos as quais eu lecionei apenas uma aluna era matogrossense. Uma explicação para isso, eu acredito que só poderemos saber através de um estudo mais aprofundado sobre as comunidades novas e as comunidades antigas matogrossenses, levando em consideração como elas estão constituídas no Estado, e como se relacionam de fato. 


\subsubsection{Consequências linguísticas da expansão territorial e populacional de Mato Grosso}

A expansão territorial e consequentemente populacional observadas no Estado de Mato Grosso ao longo de sua história, decorrentes principalmente das ondas migratórias, levaram a implicações linguísticas nesse Estado que culminaram no multilinguísmo regional.

Ilari 2006:60 fala do multilinguísmo como pano de fundo da criação do Português Brasileiro. Para este autor, a história da implantação do português no Brasil foi uma história de multilinguísmo, visto que por ocasião do descobrimento do país já vivia aqui uma população nativa estimada em seis milhões de indígenas que falavam cerca de 340 línguas não indo-européias e pertenciam a troncos linguísticos muito diferentes entre si.

Ao longo dos 40 anos pós-divisão de Mato Grosso a situação linguística do Estado foi se tornando cada vez mais complexa pela multiplicidade dos novos dialetos que vêm se juntando ao dialeto local. A expansão territorial, primeiramente no período da colonização do Estado e posteriormente no período pós-divisão, levou à expansão populacional, necessária em cada época, mas que impulsionou ondas migratórias, a partir das quais, foi inevitável o surgimento de um multilinguismo, advindo da aglomeração no Estado de diversos migrantes que traziam consigo, além da multiplicidade linguística, multiplicidade étnica e cultural.

\subsubsection{O multilinguismo como pano de fundo para o mosaico dialetal que se tornou o falar mato-grossense}

A política de povoamento em prol do desenvolvimento de Mato Grosso, que desencadeou neste Estado movimentos populacionais em que Mato Grosso passou a ser alvo de uma intensa imigração, repercutiu diretamente no sistema linguístico da região, levando ao multilinguísmo.

Todavia, dadas às condições como se deu o povoamento territorial no Estado de Mato Grosso, em que este ficou dividido entre comunidades novas e comunidades antigas, as comunidades novas foram se fixando nas regiões menos habitadas, no interior do Estado, seguindo políticas governamentais e programas lançados pelo governo federal como o PIN (Plano de Integração Nacional), o PRO-TERRA (Programa de Redistribuição de Terras e Estímulo à Agroindústria), entre outros (Siqueira, 2002). Já as comunidades antigas iam ficando mais distantes, mais afastadas das novas, conforme a extensão territorial e distribuição dos municípios no Estado.

Isso, deve ter favorecido para que as comunidades novas mantivessem inalterados seu dialeto e sua cultura e algumas comunidades antigas também tivessem ido por esse mesmo caminho, embora já se perceba em algumas comunidades antigas interferência do dialeto do migrante no seu falar, que, por razões histórica e cultural, já se traduz como um reflexo do falar do migrante na linguagem local, contribuindo para o agravamento dialetal na região,

O multilinguísmo, segundo Bagno, 2017:297 caracteriza a existência, no interior de um mesmo território - dotado ou não de soberania política - de diferentes comunidades linguísticas. É o que se observa atualmente no Estado de Mato Grosso um Estado com diversos falares, em que o dialeto local está cada vez mais se tornando uma minoria linguística em um contexto de muitilinguísmo e de contato entre línguas. 
Observa-se, em cada uma das comunidades formadas, que o espaço geográfico o qual elas se constituíram evidencia a particularidade do seu dialeto e cada variedade linguística assumida nessas comunidades difere de uma comunidade para outra como forma de responder à diversidade cultural, à natureza de sua formação, à própria base linguística preexistente no seu dialeto e à interferência de outras línguas que por qualquer razão se faz presente naquele espaço.

Diante de tudo isso, fica evidente não só o mosaico dialetal que se tornou o falar mato-grossense, como também reafirma a vontade dos migrantes de conservar no interior de suas comunidades seu dialeto e sua cultura.

O Estado de Mato Grosso apresenta no seu sistema linguístico uma situação atípica, que parece não ser percebida em nenhum outro Estado do país. Uma grande diversidade linguística com diferentes dialetos convivendo no mesmo território, formando um verdadeiro caldeirão dialetal.

Podemos dizer que o multilinguismo é natural e até previsível em um Estado bastante extenso como o Mato Grosso (com $901.420 \mathrm{~km}^{2}$ de extensão) e marcado por movimentos populacionais tão intensos e ondas migratórias tão frequentes ao longo de sua história.

É nítido observar as diversas variedades regionais convivendo juntamente com a fala do nativo mato-grossense, mostrando um Estado com uma grande diversidade linguística regional. Em cada comunidade nova formada em Mato Grosso é possível adivinhar a procedência geográfica de seus falantes pela maneira como falam. Isto é, as variedades regionais são claramente identificadas do ponto de vista diatópico, assim como é possível identificar um certo falar mato-grossense em regiões específicas do Estado, na área denominada baixada cuiabana, por exemplo, onde se concentram municípios muito antigos do Mato Grosso.

Mas, é preocupante perceber que a multiplicidade de dialetos que invadiu o Estado de Mato Grosso é grande, e que o número de falantes que no Estado fala outro dialeto que não é o dialeto local ultrapassa muito o número de falantes que fala o dialeto mato-grossense.

Isso pode representar um risco à identidade linguística e cultural do Estado, uma vez que pode trazer influências externas à cultura local, ou até mesmo causar a morte do verdadeiro dialeto mato-grossense, caso haja um contato maior dos nativos com esses tantos outros dialetos. Campos (2014, pag. 16) já demonstra essa preocupação no seu livro O Falar Cuiabano", quando diz: "Ao estudarmos o falar cuiabano em seu contexto cultural, veremos aspectos de sua constituição, sua gradual inibição e ameaça de desaparecimento diante da marcha do processo histórico sobre sua frágil singularidade”. Portanto, quando se fala em imigração, pensa-se muito no impacto que isso pode causar à região alvo, seja no aspecto cultural, social, político, linguístico.

Neste artigo, procura-se enfatizar o aspecto linguístico, o multilinguismo que se apresenta no Estado de Mato Grosso, considerando a velocidade com que se deu a expansão populacional neste Estado. Em 1979 por exemplo, depois da divisão do Estado, este contava apenas com 38 municípios, desse período até os dias atuais a expansão territorial já rendeu 103 novos municípios, que somados aos 38 antigos já conta com 141, portanto, em um intervalo de 41 anos, 103 novos municípios foram fundados no Estado, cada um deles com dialeto e cultura próprios, representando comunidades de fala das mais diversas, isso nos leva a entender melhor o mosaico dialetal que está se transformando o falar mato-grossense e o que isso futuramente poderá causar à cultura local, uma vez que o número de municípios novos ultrapassa quase três vezes o número de municípios antigos.

\footnotetext{
${ }^{2}$ A expressão "falar cuiabano" que a autora se refere é a mesma expressão utilizada para "dialeto mato-grossense."
} 
Em algumas regiões de Mato Grosso, como a região sudoeste, por exemplo, já é possível observar uma grande influência das diversas variedades regionais encontradas no Estado na fala do nativo. Assim como na capital Cuiabá, para onde convergem muitas pessoas dos diversos municípios do Estado, já se pode perceber uma grande malha linguística presente na fala do cuiabano, assim como a presença cultural e política do migrante.

Por outro lado, observa-se nas regiões, onde se encontram as cidades mais antigas, na baixada cuiabana, por exemplo, que o desenvolvimento estagnou e a densidade populacional continuou pequena, não houve crescimento, não houve um avanço significativo da pecuária nem da agricultura, de maneira que não houve um atrativo que pudesse impulsionar as migrações. Sendo assim, o dialeto dessas comunidades permaneceu quase intacto, sem sofrer influências, pois essas cidades não foram alvo do processo migratório.

Já no norte, noroeste e sudoeste do Estado, onde as políticas de incentivo pósdivisão deram impulso à interiorização e às migrações internas, o incentivo à pecuária e à agricultura, principalmente ao agronegócio, possibilitou a ocupação das fronteiras agrícolas, contribuindo para a formação de comunidades de migrantes nessas regiões. Essas comunidades conseguem manter o seu dialeto intacto, sem grandes variações, sua identidade e até mesmo sua cultura são preservadas. Observa-se até uma certa resistência por parte desses migrantes de incorporar ao seu dialeto o dialeto local.

Parece até que cada comunidade formada em terras mato-grossenses tem consciência do que uma língua ou dialeto representa para a sociedade. Que uma língua ou dialeto representa um modo muito particular de simbolização, uma vez que representa a identidade de um grupo social, em seu ambiente cultural específico para o desenvolvimento da vida, além de ser um veículo de transmissão de saberes dos mais variados e peculiares àquela comunidade. Sendo assim, analisando a postura desses migrantes em relação à língua/dialeto, parece que esses estão dispostos a preservar não só seu dialeto, como também sua cultura, sua origem. Portanto, conservar seu dialeto, sua cultura, sua origem parece ser para esses migrantes uma decisão consciente.

Ao analisar esse multilinguismo observado no falar mato-grossense, se torna até mais difícil identificar o verdadeiro dialeto de Mato Grosso em meio a tantos falares convivendo no Estado, e o pior é que cada dialeto apresenta características próprias. Aparentemente, são dialetos particulares, verdadeiros "dialetos maternos" que se espalharam pelo território mato-grossense, convivendo com o dialeto dos nativos, mas de forma harmônica, sem conflitos linguísticos. Por enquanto, não se observa no interior do Estado nenhum dialeto em disputa, ou procurando sobrepor-se a outro, sendo até fácil perceber onde termina um dialeto e começa o outro, mesmo sem um estudo mais específico que permita traçar uma divisão dialetal no Estado.

Observa-se, portanto, que as cidades mais antigas do Estado, principalmente as cidades da microrregião denominada Baixada Cuiabana mantiveram o dialeto tradicional da região, que eu diria ser o verdadeiro dialeto mato-grossense. Parece predominar nessa região uma visão conservadora do falar mato-grossense, que permanece quase homogêneo, sem grande variação.

Mas, isso é compreensível, visto que, considerando a extensão territorial do Estado de Mato Grosso, as distâncias entre os municípios novos e os antigos são grandes, isto é, a distância entre um município e outro não permite um contato maior entre comunidades, portanto, com pouca possibilidade de influências entre esses dialetos, mas que futuramente isso pode ser possível, como já se pode perceber a influência do dialeto paulista no município de Cáceres, por exemplo, e de uma diversidade de dialetos na fala da capital Cuiabá. 


\section{Considerações Finais}

Andando pelo interior de Mato Grosso e na capital Cuiabá é perceptível a existência de uma grande diversidade linguística, isto é, diversos falares convivendo em um mesmo território. Com base nessa percepção, este estudo procurando entender o que levou a essa pluralidade linguística observada no Estado de Mato Grosso, se propôs, através de um percurso histórico na região, focando nas políticas de povoamento que levaram ao crescimento populacional no Estado, entender a evolução do falar matogrossense com a presença de uma gama considerável de migrantes nesse Estado desde sua colonização até o momento atual e o efeito que isso causou no sistema linguístico da região.

Verificou-se que o Estado de Mato Grosso desde a sua constituição é marcado por ondas migratórias que culminou com um acúmulo de comunidades de fala diferentes, em que cada novo município ou comunidade fundada depois dos anos 1970 apresenta um dialeto muito peculiar, completamente diferente do dialeto das cidades mais antigas do Estado, com características da fala de seu fundador. Percebe-se também que essas novas comunidades conservam não só o seu dialeto como também sua cultura, que transmitem para as novas gerações.

De modo que, atualmente, percebe-se no Estado de Mato Grosso não só uma multiplicidade linguística como uma multiplicidade cultural e étnica, representadas por nativos e migrantes, numa convivência aparentemente pacífica, em que as transformações percebidas são unilaterais, apenas por parte do nativo.

Essas evidências mostram que o dialeto mato-grossense já vem sofrendo alterações marcantes ao longo de sua história, considerando o crescimento populacional no Estado, provocado pela imigração que culminou na pluralidade dialetal. Assim como mostram que o migrante emigrado para esse Estado mantém seu dialeto de origem inalterado.

Portanto, essa percepção aponta para indícios de um processo de difusão dialetal em cidades antigas de Mato Grosso, que pode levar o dialeto mato-grossense, com o tempo, a assumir uma nova composição, diferente da forma como foi constituído, ou seja, levar o falar mato-grossense a uma perda da identidade linguística, visto que essas transformações dialetais percebidas, através desse espaço multilíngue, faz deste um Estado com diversos falares. Assim como, o comportamento do migrante de impor ao nativo não só sua língua como sua cultura pode levar o mato-grossense também a uma perda de identidade cultural.

\section{REFERÊNCIAS}

BAGNO, Marcos. Língua, Linguagem, Linguística: pondo os pingos nos II. 1 ed. - São Paulo: Parábola Editorial, 2014.

2017.

. Dicionário Crítico de Sociolinguística. 1 rd. - São Paulo: Parábola Editorial,

BLOM , J. P. \& GUMPERZ J. J. 1972/1986. O Significado Social na Estrutura Linguística: Alternância de Código na Noruega. In: RIBEIRO, Branca T. \& GARCEZ, Pedro M. (org.) Sociolinguística Interacional.

BORTONI-RICARDO, Stella Maris. Nos cheguemu na escola, e agora?: sociolinguística \& educação. São Paulo: Parábola Editorial 2005.

CALVET, Louis-Jean. Sociolingüística: uma introdução crítica. São Paulo: Parábola 2002. 
CAMPOS, Cristina. O Falar Cuiabano. Cuiabá-MT: Carlini \& Caniato Editorial, 2014. ELIA, Sílvio. Fundamentos Histórico-Linguísticos do Português do Brasil. Rio de Janeiro: Lucerna, 2003.

FERREIRA, João Carlos Vicente. Mato Grosso e Seus Municípios. Cuiabá-MT: Secretaria de Estado de Educação, 2001.

GUMPERZ, J. J. \& HYMES, D. 1972/1986. Directions in sociolinguistics: The ethnografhy of communication. New York: Holt, Rinehart \& Winton.

ILARI, Rodolfo \& BOSCO, Renato. O português da Gente: a língua que estudamos a língua que falamos. - São Paulo: Contexto, 2006.

SEPLAN - Governo do Estado de Mato Grosso - Secretaria de Planejamento e Coordenação Geral. Anuário Estatístico de Mato Grosso. Cuiabá-MT: Carrión \& Carracedo - Editores Associados, 2005.

RIBEIRO, Branca T. \& GARCEZ, Pedro M. (org.) Sociolinguística Interacional. - 2 ed. - São Paulo: Edições Loyola, 2013. . A dinâmica de um processo de mudança: a variação entre [ãw] e [õ] final em Mato Grosso. - Tese de Doutorado. - Rio de Janeiro: UFRJ, 2005.

SIQUEIRA, Elizabeth Madureira. História de Mato Grosso: da ancestralidade aos dias atuais. Cuiabá-MT: Entrelinhas, 2002.

Recebido em: janeiro de 2021.

Aprovado em: março de 2021.

\section{Como citar este trabalho:}

SILVA, M. P. Mato Grosso: um Estado diversos falares. Traços de Linguagem. V. 4, n. 2, p. 64-80, 2020. 